\title{
Two-Dimensional Liquid Chromatography (2D-LC) for Biopharmaceuticals Samanidou VF*
}

Department of Chemistry, Laboratory of Analytical Chemistry, Aristotle University of Thessaloniki, 54124 Thessaloniki, Greece

*Corresponding author: Victoria F. Samanidou, Department of Chemistry, Laboratory of Analytical Chemistry, Aristotle University of Thessaloniki, 54124 Thessaloniki, Greece, Tel: +30231997698; Fax: +302310997719; E-mail: samanidu@chem.auth.gr

Received date: May 14, 2018; Accepted date: May 17, 2018; Published date: May 24, 2018

Copyright: (c) 2018 Samanidou VF. This is an open-access article distributed under the terms of the Creative Commons Attribution License, which permits unrestricted use, distribution, and reproduction in any medium, provided the original author and source are credited.

\section{Editorial}

Biopharmaceuticals, such as monoclonal antibodies (mAbs), interferons/cytokines, vaccines etc contribute progressively more to clinical practice. They are complex macromolecules produced from living cells by means of biotechnology, usually produced to treat lifethreatening diseases, such as tumors, autoimmune diseases, diabetes, etc. Compared to traditional drugs, biopharmaceuticals are much larger in size, which ranges from 2,000 to 2,000,000 Daltons, while traditional pharmaceuticals are typically within the range 100-1500 Daltons. Another significant difference between them is the number of active sites (functional groups) in biopharmaceuticals, which is significantly higher usually 10-2000. All these characteristics make their investigation of great analytical challenge. Due to their complexity, biopharmaceuticals require multiple modes of chromatographic separations. Moreover the fact that exact copies of biopharmaceuticals cannot be produced; this results to the production of biosimilars that refer to drugs with similar physicochemical characteristics, as well as efficacy and safety with the originators. The ongoing development in biosimilar manufacturing has led to the demand for complementary analytical methods in order to achieve the efficient comparison with originators. At present there are more than 200 approved biopharmaceuticals in the market and this is predicted to increase. Although monoclonal antibodies are the prevailing biopharmaceuticals, novel drugs like antibody drug conjugates (ADCs) have become of particular oncological interest. These are capable to deliver the chemotherapeutic cytotoxic agent directly to the tumor site antigen. By this approach the risk of damaging healthy tissues is intensely reduced. Thereby they take advantage of the benefits of large molecule specificity with small molecule toxicity [1-5].

The analysis of biopharmaceuticals is apparently necessary in many steps of drug development and manufacture including pre-clinical research, clinical trials, understanding of molecular mechanisms, target identification in diseases, pharmacokinetics etc.

Their comprehensive analysis involves multiple liquid chromatography techniques. Large molecules were always of field of increased challenge to the analytical scientists and especially to chromatographers. And this challenge is enhanced due to the increasing interest in pharmaceutical research and development.

In that direction two dimensional liquid chromatography (LC $\times$ LC or $2 \mathrm{D}-\mathrm{LC}$ ) can provide complementary information on the identity and purity of compounds, therefore it is a powerful tool in the analysis of biopharmaceuticals. As such it has been already used in peptide mapping of therapeutic mAbs (originators and biosimilars) in research and development studies as well as in the Quality control/Quality Assurance sectors [6].

Two dimensional liquid chromatographic analysis includes the partial (heart-cutting) or complete (comprehensive) analysis by two separation mechanisms, either off-line or on-line. Different separation modes eg ion exchange, hydrophilic-lipophilic can be combined with reversed phase chromatography prior to UV or MS detection [7].

The heart-cutting 2D-LC technique can provide information on peak purity even in cases where a co-eluting impurity present is present at low concentrations e.g. at $0.8 \%$ that could not be detected using traditional methods [8].

Two-dimensional systems (2D-LC/MS) can be also applied in cases where fast desalting using an MS compatible mobile phase is necessary prior to MS analysis. Thereby fractions containing the compounds of interest are separated by the first dimension using an MS incompatible mobile phase, then sent to a second dimension HPLC method [9].

Quality in terms of safety and efficacy issues in the final drug product in biopharmaceuticals can be reassured by modern analytical approaches and instrumentation as for example for characterizing protein aggregation of crude in-process bioreactor samples $[8,10]$.

Recent advances in modern instrumentation make all these combinations commercially available. Switching valves as well as suitable software offer the possibility to adapt two-dimensional procedures after only minor modifications to existing HPLC equipment.

\section{References}

1. Janowitz $\mathrm{T}$ (2011) Biopharmaceuticals and monoclonal antibodies in oncology trials-a cross-sectional analysis. Protein Eng Des Sel 24: 105-111.

2. Ecker DM, Jones SD, Levine HL (2015) The therapeutic monoclonal antibody market. MAbs 7: 9-14.

3. Sorensen M, Harmes DC, Stoll DR, Staples GO, Fekete S, et al. (2016) Comparison of originator and biosimilar therapeutic monoclonal antibodies using comprehensive two-dimensional liquid chromatography coupled with time-of-flight mass spectrometry. mAbs 8: 1224-1234

4. McGrath NA, Brichacek M, Njardarson JT (2010) A graphical journey of innovative organic architectures that have improved our lives. J Chem Ed 87: 1348-1349.

5. http://njardarson.lab.arizona.edu/sites/njardarson.lab.arizona.edu/files/ 2016Top200PharmaceuticalPrescriptionSalesPosterLowResV2.pdf

6. Vanhoenacker G, Vandenheede I, David F, Sandra P, Sandra K (2015) Comprehensive two-dimensional liquid chromatography of therapeutic monoclonal antibody digests. Anal Bioanal Chem 407: 355-366.

7. Sandra K, Vandenheede I, Steenbeke M, Vanhoenacker G, Sandra P (2017) Characterizing monoclonal antibodies and antibody-drug conjugates using 2D-LC-MS. LC-GC Europe 30: 149-157.

8. Lee C, Zang J, Cuff J, McGachy N, Natishan TK, et al. (2013) Application of heart-cutting $2 \mathrm{~d}-\mathrm{lc}$ for the determination of peak purity for a chiral pharmaceutical compound by HPLC. Chromatographia 76: 5-11.

9. Luo H, Zhong W, Yang J, Zhuang P, Meng F, et al. (2017) 2D-LC as an online desalting tool allowing peptide identification directly from MS unfriendly HPLC methods. J Pharmac Biomed Anal 137: 139-145. 
Citation: Samanidou VF (2018) Two-Dimensional Liquid Chromatography (2D-LC) for Biopharmaceuticals. Pharm Anal Acta 9: e192. doi: $10.4172 / 2153-2435.1000 \mathrm{e} 192$

Page 2 of 2

10. Williams A, Read EK, Agarabi CD, Lute S, Brorson KA (2017) Automated 2D-HPLC method for characterization of protein aggregation with in-line fraction collection device. J Chromatogr B 1046: 122-130. 